\title{
Quasi-Coordinated Search for a Randomly Located Target
}

\author{
Teamah AEAM, Gabal HMA and Elbery AB*
}

Department of Mathematics, Faculty of Science, Tanta University, Tanta, Egypt

\begin{abstract}
In this paper we describe the quasi-coordinated search problem for a lost located target on one of $n$-disjoint lines in which any information of the target position is not available to the searchers all the time. Every two searchers on each line cooperate together to find the location of the lost target as soon as possible where the motion of every two searchers on each line are independent for the motion of the other searchers on another lines. The purpose of this paper is to formulate a search problem and find the expected value of the first meeting time between one of the searchers and the target. Also, we show the existence of the optimal search plan which minimizes the expected value of the first meeting time and find it.
\end{abstract}

Keywords: Coordinated search; Optimal search theory; Real line

\section{Introduction}

Search problems are still largely of the same form as in 1942: a single target is lost and the problem is to find it efficiently [1]. Generally, the searching for a lost target either located or moved is often a timecritical issue that is when the target is very important. The prime focus is to find and search for the cast ways in the smallest possible amount of time [2]. The problem considered in this paper: the searchers coordinate their search for a stationary target with the objective of minimizing [3] the expected time until one searchers (one of them) detects the target. The meeting point (origin point) is the point where the searchers check back after each period of searching to find out if the other searcher has already located the target. Some problems of search may impose using more than one searcher such as [4]: when we search for a valuable target (e.g., the two parents searching for a lost child. The child is equally likely to be anywhere on one of $n$-disjoint roads), or search for a serious target (e.g., a car filled with explosives in one of $\mathrm{n}$-disjoint roads) or search for any enemy or a mine on a battlefront whose extension may approximated by a straight line, or searching for a bomb in known region or a life raft on the ocean. This kind of search problems has recently various applications such as: the search for missing boats, lost persons on roads, petroleum or gas reservoirs underground [5] and so on. We aim to minimize the expected value of the first meeting time between one of the searchers and the target.

In the present paper we take the search region to be the real lines, with the origin point as the starting and meeting point of the searchers [6]. We consider target distributions that are symmetric and unsymmetric about zero, so that we may assume that one searcher always searches to the right, and the other to the left [7]. They return to zero after searching successively larger common distances, until the object is found. The problem is to find the expected the expected value of the first meeting time between one of the searchers and the target. There is obviously some similarity between this problem and the wellknown Linear Search Problem which has been studied extensively [8] and also Abd-Elmoneim and Hamdy [8]. In that problem every two searchers and start together looking for the target from the origin of the line $\mathrm{Lj}, \mathrm{j}=1,2, \ldots, \mathrm{n}$. The target is located according to symmetric or unsymmetric distribution on every line, our aim is to minimize the expected value of some function of the time taken to find a target according to a known distribution on the line [2-4]. An optimizing searcher [9] goes to successively increasing distances in alternating directions until the target is found. In our problem, the searchers could stay together and follow the optimal solution of the Linear Search Problem [10].

On the other hand, when the target is located on the real line according to a known probability distribution. Every two searchers on each line start from the origin to find the target

in minimal expected time, we assume that the speed of each searchers equal one. The target can be detected only if the searcher reaches the target. In an earlier work, this problem has been studied extensively in many variations [11-17]. The coordinated search problem on an interval when the distribution of the lost target is known, and unsymmetric about zero has been studied [18]. Also, the coordinated search problem for a randomly located target on one of two lines and the target having a certain symmetric distribution around the origin has been studied [19]. Recently, this technique has been illustrated in the plane when the target has symmetric or unsymmetric distribution $[20,21]$. There is obviously some similarity between this problem and the well-known linear search problem.

This paper is organized as follows. In this paper we formulate the problem. The search plan and expected value of the first meeting time between one of the searchers and the target on a line, we will introduce two parts: the aim of the first part is to study the coordinated search problem for a located target on one of $\mathrm{n}$-disjoint lines which has [22] symmetric distribution, while in the second part we also study the same problem which has unsymmetric distribution, we will calculate the expected value of the time of finding the target and existence of an optimal search path. Also we referred to a special cases when $n=1$ and $\mathrm{n}=2$. Finally, the paper concludes with a discussion of the results and directions for future research [23].

\section{Problem Formulation}

The problem under study can be formally described as follows: We

*Corresponding author: Elbery $\mathrm{AB}$, Department of Mathematics, Faculty of Science, Tanta University, Tanta, Egypt, Tel: 2040 3317928; E-mail: Asmaa.elbery@yahoo.com

Received March 25, 2018; Accepted April 11, 2018; Published April 15, 2018

Citation: Teamah AEAM, Gabal HMA, Elbery AB (2018) Quasi-Coordinated Search for a Randomly Located Target. J Appl Computat Math 7: 395. doi: 10.4172/2168-9679.1000395

Copyright: $(2018$ Teamah AEAM, et al. This is an open-access article distributed under the terms of the Creative Commons Attribution License, which permits unrestricted use, distribution, and reproduction in any medium, provided the original author and source are credited. 
have two searchers $S_{2 j-1}$ and $S_{2, j}, j=1,2, . . n$, start the searching process from the origin of the line $L j, j=1,2, \ldots, n$, respectively, as in Figure 1. Each searchers $S_{2 j-1}$ and $S_{2 j}$ of them return to zero after searching successively common distances. The two searchers $S_{2 j-1}$ and $S_{2, j}$ would conduct his search in the following manner: Start together looking for the target from the origin $O_{j}$ of the line $L j, j=1,2, \ldots, n$. The searcher $\mathrm{S}_{2 \mathrm{j}-1}$ searches to the (right) of $\mathrm{O}_{\mathrm{j}}$ and go to $\mathrm{a}_{1 \mathrm{j}}$, and another searcher $\mathrm{S}_{2, \mathrm{j}}$ searches to the (left) of the starting point $\mathrm{O}_{j}$ and go to $\mathrm{b}_{1 j}$, then turn back to the origin point $\mathrm{O}_{j}$ and tell them if they detect the target or not. Retrace the steps again to the origin point $\mathrm{O}$ to the (right) and the (left) and go to $a_{i 2}$ and respectively, then turn back to the origin $O_{j}$ and so on until one of them detects the target. The target is located according to symmetric or unsymmetric distribution on every line $\mathrm{L}$. The searcher $\mathrm{S}_{2 \mathrm{i}-1}$ searches with speeds go to the (right) and the searcher $\mathrm{S}_{2 \mathrm{j}}$ searches with speeds $V_{2 j}$ go to the (left), where $V_{1}=V_{2}=\ldots=V_{n}=1$.

Either two searchers $S_{2 j-1}$ and $S_{2 j}$ detect the target on the line $\mathrm{Lj}$.

On $L j, j=1,2, \ldots, n$ the searchers $S_{2 j-1}$ and $S_{2 j}$ follow the search paths $\left\{a_{i j}, i \geq 0\right\}$ and $\left\{b_{i j i}, i \geq 0\right\}$ respectively to search the target. The search path $a_{i}$ of the $S_{2 j-1}$ are completely defined by a sequence $\left\{\mathrm{a}_{\mathrm{ij}}, \mathrm{i} \geq 0\right\}$ and the search path $b_{j}$ of the $S_{2 j}$ are completely defined by a sequence $\left\{b_{j i}, i \geq 0\right\}$ where $i$ is a nonnegative integer. Let the search plan on line $\mathrm{L}_{\mathrm{j}}$ be represented by $\Phi_{j}=\left\{a_{j i}, b_{j i}\right\} \widehat{\Phi}$, where $\Phi$ is the set of all search plans.

Figure 1 gives an illustration of the search plan which the 2n-searchers $S_{2 j-1}$ and $S_{2 j}, j=1,2, . . n$ follow it. Moreover, it is to be noted that is the set of search plans available to $\mathrm{S}_{2 \mathrm{j}-1}$ and $\mathrm{S}_{2 \mathrm{j}}$ is the set $\Phi_{j} \in \Phi$, where $\widehat{\Phi}$ is the set of all search plans such that:

$\left.\phi_{j}=\left\{\left\{a_{j i}, b_{i j}\right\}\right\}_{i \geq 0}: \ldots b_{j 3}<b_{j 2}<b_{j 1}<O_{j}=b_{j 0}=a_{j 0}=0<a_{j 1}<a_{j 2}<a_{j 3}<\ldots.\right\}$

Where,

$$
\begin{aligned}
& c_{j}=\lim _{i \rightarrow \infty} b_{j i} \\
& \text { And } \\
& d_{j}=\lim _{i \rightarrow \infty} a_{j i}, \forall i \geq 0, j=1,2, \ldots ., n .
\end{aligned}
$$

The search plan of the searchers for $\mathrm{n}$ - lines represented by $\Phi=\left(\Phi_{1}, \Phi_{2}, \ldots . \Phi_{n}\right) \in \widehat{\Phi}$. The first meeting time between one of the searchers and the target on a line is a random variable. There is a known probability measure $\gamma=\gamma_{1}+\gamma_{2}+\ldots+\gamma_{n}$ on $\left[c_{1}, d_{1}\right] \cup\left[C_{2}, d_{2}\right] \cup \ldots$ .$\cup\left[C_{n}, d_{n}\right]$ which describes the position of the target, where $\gamma_{i}, j=1,2, \ldots, n$ are the probability measure induced by the position of the target on $\left[\mathrm{C}_{\mathrm{j}}, \mathrm{d}_{\mathrm{j}}\right]$ and $\sum_{j=1}^{n} \gamma_{j}\left(C_{j}, d_{j}\right)=1$.

The searchers $S_{2 j-1}$ and $S_{2 j}$ return to the origin point after searching successively common distances until one of searchers detects the target. Our aim is to calculate the first meeting time between one of searchers and the lost target. Also, we wish to find the optimal search plan which minimizes the expected value of the time.

We shall study the coordinated search problem when the target is randomly located on one of $\mathrm{n}$ disjoint lines. We will introduce two cases : the aim of the first case is to study the distribution of the lost target is symmetric around the origin point on every line of $n$ disjoint lines, while the second case we also study the distribution of the lost target which has unsymmetrical about the origin point.

In this problem, let $\mathrm{D}_{2 \mathrm{j}-1}\left(\right.$ or $\left.\mathrm{D}_{2 \mathrm{j}}\right), \mathrm{j}=1,2, \ldots, n$ be the distances for the searchers $S_{2 j-1}\left(S_{2 j}\right)$ ), respectively, to return to the origin (if $V_{1}=V_{2}=\ldots$ $\left.\mathrm{V}_{\mathrm{n}}=1\right), \mathrm{D}_{2 \mathrm{j}-1}\left(\right.$ or $\mathrm{D}_{2 \mathrm{j}}$ ) represent the time, and let $\mathrm{D}(\phi)$ be the time for the searchers to return to the origins after one of them the target.

We assume that the probability of the position of the target at each point in $\left[c_{i}, d_{j}\right]$ can be calculated from a given distribution function $F$ $\left(\mathrm{x}_{\mathrm{j}}\right)$ with a density function $\mathrm{f}_{\mathrm{j}}\left(\mathrm{x}_{\mathrm{j}}\right)$ which is symmetric or unsymmetric about the origin of the line $\mathrm{Lj}$.

\section{Case (1): Symmetric coordinated search for a randomly located target on the one of $\mathbf{n}$ - disjoint lines}

In this case we consider the searchers $S_{2 j-1}$ and $S_{2 j}, j=1,2, \ldots, n$ start together looking for the target from the origin point $\mathrm{O}_{j}$ of the line $\mathrm{Lj}$ and the position of the lost target has a know symmetric distribution on every line $\mathrm{Lj}$, where the symmetric distribution of the target on $\mathrm{L}_{2}$ differs from symmetric distribution of the target on and so on for other lines because the lost target has difference symmetric distributions on all lines, every two searchers $S_{2 j-1}$ and $S_{2 j}$ start together looking for the

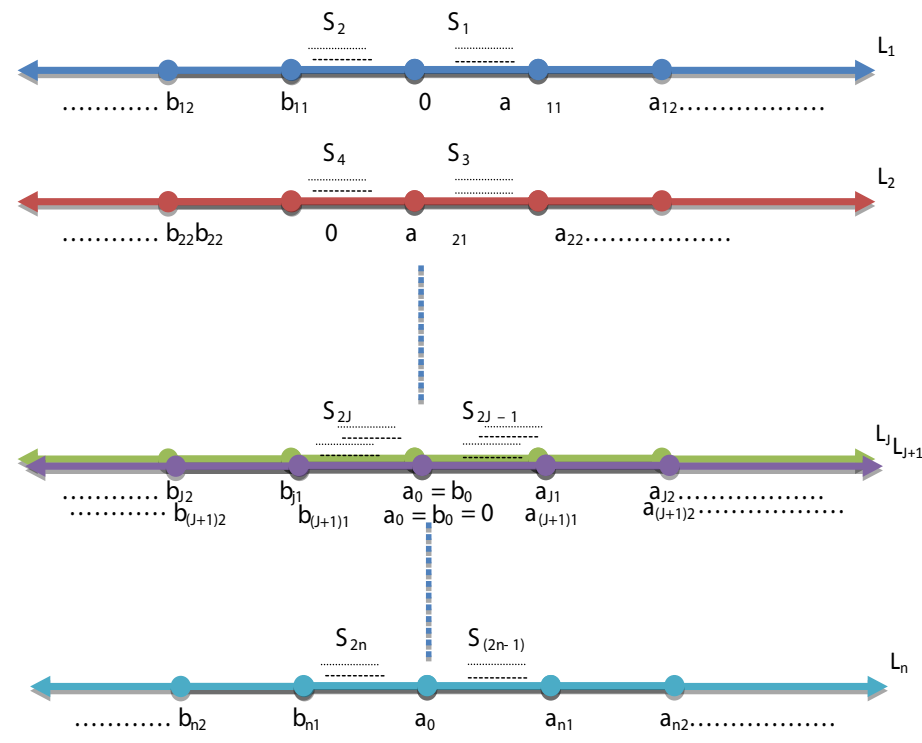

Figure 1: The search plan $\phi=\left(\phi_{1}, \phi_{2}, \ldots, \phi_{n}\right)$ of the searchers $S_{2 j-1}$ and $S_{2 j}, j=1,2, \ldots . n$. 
Citation: Teamah AEAM, Gabal HMA, Elbery AB (2018) Quasi-Coordinated Search for a Randomly Located Target. J Appl Computat Math 7: 395. doi: 10.4172/2168-9679.1000395

lost target from the origin $\mathrm{O}_{\mathrm{j}}$ on the line $\mathrm{Lj}$, they continuously a long in both directions of the starting point $\mathrm{O}_{j}$ on the line $\mathrm{Lj}$. The searcher $\mathrm{S}_{2 \mathrm{j}-1}$ searches to the right of $\mathrm{O}_{j}$ and goes to $\mathrm{a}_{\mathrm{j} 1}$ the searcher $\mathrm{S}_{2 \mathrm{j}}$ searches to the left of the starting point $\mathrm{O}_{j}$ and goes to $b_{i 1}$, then the searcher $S_{2 j-1}$ and $\mathrm{S}_{2 \mathrm{j}}$ return to the origin point $\mathrm{O}_{\mathrm{j}}$ and tell them if they detect the target or not, in the same time. they start again from the origin point to the right and the left and they return to the origin point $\mathrm{O}_{j}$ and so on until one of them detects the target. The two searchers $S_{2 i-1}$ and $S_{2 j}$ on the line $\mathrm{Lj}$ move with the same distances according to the probability of the position of the target, i.e., $a_{j i}=\left|b_{j i}\right|,\left(b_{j i}=-a_{j i}\right)$ where $\mathrm{a}_{\mathrm{ji}}$ refers to the distance which the searcher $S_{2 j-1}$ far from the origin of $L j$ at the beginning of the search, and $b_{\mathrm{ji}}$ refers to the distance which the searcher $\mathrm{S}_{2 \mathrm{j}-1}$ far from the origin of $\mathrm{Lj}$ at the beginning of the search.

In the following theorem we assume that $\mathrm{D}_{2 \mathrm{j}-1}=\mathrm{D}_{2 \mathrm{j}}$ according to the symmetric distribution of the lost target on the line $\mathrm{Lj}$.

\section{Theorem 1}

The expected value of the time for the searchers to return the origins for all lines, until one of them has detects a target is given by:

$$
\begin{aligned}
& E[D(\Phi)]=4 \sum_{i=1}^{\infty} \sum_{j=1}^{n} a_{j i}\left[\gamma_{j}\left(c_{j}, d_{j}\right)-F_{j}\left(a_{j(i-1)}\right)\right] \\
& \text { and } \\
& E[D(\Phi)]=4 \sum_{i=1}^{\infty} \sum_{j=1}^{n} b_{j i}\left[\gamma_{j}\left(c_{j}, d_{j}\right)-F_{j}\left(b_{j(i-1)}\right)\right] \\
& \text { Proof }
\end{aligned}
$$

If the target is detected on the line $\mathrm{Lj}$ we find:
If the target lies in $\left[0, \mathrm{a}_{\mathrm{j} 1}\right]$, then $D_{2 j}=2\left|b_{j 1}\right|+2\left|b_{j 2}\right|=2 a_{j i}+2 a_{j 2}$ and so on,

If the target lies in $\left[b_{j 1}, 0\right]$, then $D_{2 j-1}=2 a_{j 1}$.

If the target lies in $\left[b_{i 2}, b_{j 1}\right]$, then $D_{2 j-1}=2 a_{i 1}+2 a_{i 2}$,

and so on.

Hence, we can calculate $\mathrm{E}[\mathrm{D}(\phi)]$ as follows,

$$
\begin{aligned}
& E[D(\Phi)]= \sum_{j=1}^{n} 2 a_{j 1}\left[0, a_{j 1}\right)+\gamma_{j}\left(\mathrm{~b}_{j 1}, 0\right) \\
&+\left(2 a_{j 1}+2 a_{j 2}\right)\left[\gamma_{j}\left(a_{j 1}, a_{j 2}\right)+\gamma_{j}\left(b_{j 2}, b_{j 1}\right)\right] \\
&+\left(2 a_{j 1}+2 a_{j 2}+2 a_{j 3}\right)\left[\gamma_{j}\left(a_{j 2}, a_{j 3}\right)+\gamma_{j}\left(b_{j 3}, b_{j 2}\right)\right]+ \\
&= 2 a_{j 1} \gamma_{j}\left(\mathrm{c}_{j}, \mathrm{~d}_{j}\right)+2 \mathrm{a}_{j 2}\left[\gamma_{j}\left(c_{j}, d_{j}\right)-\gamma_{j}\left(\mathrm{~b}_{j 1}, \mathrm{a}_{j 1}\right)\right] \\
&+2 a_{j 3}\left[\gamma_{j}\left(\mathrm{c}_{j}, \mathrm{~d}_{j}\right)-\gamma_{j}\left(b_{j 2}, a_{j 2}\right)\right]+\ldots . . \\
&=\sum_{j=1}^{n}\left\{2 a_{j 1}\left[\begin{array}{l}
\left.\gamma_{j}\left(0, a_{j 1}\right)+\gamma_{j}\left(a_{j 1}, a_{j 2}\right)+\gamma_{j}\left(a_{j 2}, a_{j 3}\right)+\ldots\right] \\
+\gamma_{j}\left(b_{j 1}, 0\right)+\gamma_{j}\left(\mathrm{~b}_{j 2}, \mathrm{~b}_{j 1}\right)+\gamma_{j}\left(\mathrm{~b}_{j 3}, \mathrm{~b}_{j 2}\right) \ldots . . .
\end{array}\right]\right. \\
&+2 a_{j 2}\left[\begin{array}{l}
\gamma_{j}\left(\mathrm{a}_{j 1}, a_{j 2}\right)+\gamma_{j}\left(\mathrm{a}_{j 2}, a_{j 3}\right)+\ldots . \\
+\gamma_{j}\left(\mathrm{~b}_{j 2}, \mathrm{~b}_{j 1}\right)+\gamma_{j}\left(b_{j 3}, \mathrm{~b}_{j 2}\right)+\ldots .
\end{array}\right] \\
&+2 a_{j 3}\left[\begin{array}{l}
\left.\gamma_{j}\left(\mathrm{a}_{j 2}, a_{j 3}\right)+\gamma_{j}\left(\mathrm{a}_{j 3}, a_{j 4}\right)+\ldots\right] \\
\left.+\gamma_{j}\left(\mathrm{~b}_{j 3}, \mathrm{~b}_{j 2}\right)+\gamma_{j}\left(\mathrm{~b}_{j 4}, \mathrm{~b}_{j 3}\right)\right]
\end{array}\right. \\
&=\sum_{j=1}^{n}\left\{2 \mathrm{a}_{j 1} \gamma_{j}\left(c_{j}, \mathrm{~d}_{j}\right)+2 \mathrm{a}_{j 2}\left[\begin{array}{l}
\gamma_{j}\left(\mathrm{c}_{j}, \mathrm{~d}_{j}\right)-\gamma_{j}\left(\mathrm{~b}_{j 1}, a_{j 1}\right)+ \\
\left.2 a_{j 3}\left[\gamma_{j}\left(\mathrm{c}_{j}, \mathrm{~d}_{j}\right)-\gamma_{j}\left(\mathrm{~b}_{j 2}, a_{j 2}\right)+\ldots\right]\right]
\end{array}\right.\right. \\
&=2 \sum_{i=1}^{\infty} \sum_{j=1}^{n} a_{j i}\left[\gamma_{j}\left(c_{j}, d_{j}\right)-\gamma_{j}\left(b_{j(i-1)}, a_{j(i-1)}\right)\right] \\
&=2 \sum_{i=1}^{\infty} \sum_{j=1}^{n} a_{j i}\left[\gamma_{j}\left(c_{j}, d_{j}\right)-F_{j}\left(a_{j(i-1)}+F_{j}\left(\mathrm{~b}_{j(i-1)}\right)\right]\right. \\
&=2 \sum_{i=1}^{\infty} \sum_{j=1}^{n} a_{j i}\left[\gamma_{j}\left(c_{j}, d_{j}\right)-F_{j}\left(a_{j(i-1)}+F_{j}\left(-a_{j(i-1)}\right)\right]\right.
\end{aligned}
$$

From the properties of the symmetric distribution, we can say that its cumulative distribution function satisfies

$\gamma_{j}\left(c_{j}, d_{j}\right)-F_{j}(x)=F_{j}(-x), x \geq 0$

Then

$$
E[D(\Phi)]=4 \sum_{i=1}^{\infty} \sum_{j=1}^{n} a_{j 1}\left[\gamma_{j}\left(\mathrm{c}_{j}, \mathrm{~d}_{j}\right)-F_{j}\left(\mathrm{a}_{j(i-1)}\right]\right.
$$

By similar way we can prove equation (2).

\section{Special cases}

Case 1: if $\mathrm{n}=1$ from (1) we have:

$$
E[D(\Phi)]=4 \sum_{i=1}^{\infty} a_{i}\left(1-\mathrm{F}\left(a_{(i-1)}\right)\right)
$$

\section{Case 2}

If the target is located according to a known symmetric distribution on one of two disjoint lines $\mathrm{L}_{1}$ and $\mathrm{L}_{2}$, where the distribution of the lost target is the same on lines $\mathrm{L}_{1}$ and $\mathrm{L}_{2}$ we can get:

$$
E[D(\Phi)]=4 \sum_{i=1}^{\infty} a_{1 i}\left[\gamma_{1}\left(c_{1}, \mathrm{~d}_{1}\right)-F_{1}\left(a_{1(i-1)}\right)+4 \sum_{i=1}^{\infty} a_{2 i}\left[\gamma_{2}\left(\mathrm{c}_{2}, \mathrm{~d}_{2}\right)-\mathrm{F}_{2} a_{20 i-1}\right]\right]
$$

We obtain the same results see [19].

\section{Definition}

$$
\begin{aligned}
& \text { If } \Phi=\left(\Phi_{1}, \Phi_{2}, \ldots \Phi_{n}\right) \in \widehat{\Phi} \\
& E[D(\Phi)]=\inf \{\mathrm{E}[D(\Phi) ; \Phi \in \widehat{\Phi}]\}
\end{aligned}
$$

Where $\Phi$ is the set of all search plan.

\section{Theorem 2}

Let $\mathrm{F}_{\mathrm{j}}\left(\mathrm{x}_{\mathrm{j}}\right)$ be the distribution function of a continuous random variable $\mathrm{x}_{\mathrm{j}}$ with a density function $\mathrm{f}_{\mathrm{j}}\left(\mathrm{x}_{\mathrm{j}}\right)$ and if $\Phi=\left(\Phi_{1}, \Phi_{2}, \ldots \Phi_{n}\right) \in \widehat{\Phi}$ is an optimal search plan, then:

$$
a_{j(i+1)}=\frac{\gamma_{1}\left(c_{j}, d_{j}\right)-F_{j}\left(a_{j(i-1)}\right)}{f_{j}\left(a_{j i}\right)} i=1,2, \ldots \quad j=1,2, \ldots, \ldots n
$$

And

$$
b_{j(i+1)}=\frac{\gamma_{1}\left(c_{j}, d_{j}\right)-F_{j}\left(b_{j(i-1)}\right)}{f_{j}\left(b_{j i}\right)} i=1,2, \ldots \quad j=1,2, \ldots, \ldots n
$$

Proof

From (1) we have:

$$
\begin{aligned}
& E[D(\Phi)]=4 \sum_{j=1}^{x} \sum_{i=1}^{n} a_{j}\left[\gamma_{1}\left(c_{j}, d_{j}\right)-F_{j}\left(a_{j(-1)}\right)\right] \\
& =4 \sum\left\{a_{i 1}^{\infty}\left[\gamma_{1}\left(c_{1}, d_{1}\right)-F_{1}\left(a_{1(-1)}\right)\right]+a_{2 i}\left[\gamma_{2}\left(c_{2}, d_{2}\right)-F_{2}\left(a_{2(-1)}\right)\right]+a_{3 i}\left[\gamma_{3}\left(c_{3}, d_{3}\right)\right]-F_{3}\left(a_{3(-1)}\right)\right. \\
& =4\left\{\mathrm{a}_{11}\left[\gamma_{1}\left(c_{1}, d_{1}\right)-F_{1}(0)\right]+\mathrm{a}_{12}\left[\gamma_{1}\left(c_{1}, d_{1}\right)-F_{1}\left(a_{11}\right)\right]+\mathrm{a}_{13}\left[\gamma_{1}\left(c_{1}, d_{1}\right)-F_{1}\left(a_{12}\right)\right]+\right. \\
& \ldots+\mathrm{a}_{12}\left[\gamma_{2}\left(c_{2}, d_{2}\right)-F_{2}(0)\right]+\mathrm{a}_{22}\left[\gamma_{2}\left(c_{2}, d_{2}\right)-F_{2}\left(a_{21}\right)\right]+\mathbf{a}_{23}\left[\gamma_{2}\left(c_{2}, d_{2}\right)-F_{2}\left(a_{22}\right)\right]+\ldots+a_{31}\left[\gamma_{3}\left(c_{3}, d_{3}\right)-F_{3}(0)\right]
\end{aligned}
$$

Hence, we can get the following:

$$
\frac{\partial E(D(\Phi))}{\partial a_{11}}=4\left\{\gamma_{1}\left(c_{1}, d_{1}\right)-\mathrm{F}_{1}(0)-\mathrm{a}_{12} f(0)-\mathrm{a}_{12} f\left(a_{11}\right)\right\}=0
$$

Which leads to

$$
\begin{aligned}
& \gamma_{1}\left(c_{1}, d_{1}\right)-F_{1}(0)=a_{12} f_{1}\left(a_{11}\right) \\
& a_{12}=\frac{\gamma_{1}\left(c_{1}, d_{1}\right)-F_{1}(0)}{f_{1}\left(a_{11}\right)}
\end{aligned}
$$

Also, 
$\frac{\partial E(D(\Phi))}{\partial a_{12}}=4\left\{\gamma_{1}\left(c_{1}, d_{1}\right)-\mathrm{F}_{1}\left(a_{11}\right)-\mathrm{a}_{13} f_{1}\left(a_{12}\right)\right\}=0$

$\gamma_{1}\left(c_{1}, d_{1}\right)-F_{1}\left(a_{11}\right)=a_{13} f_{1}\left(a_{12}\right)$

due to

$a_{13}=\frac{\gamma_{1}\left(c_{1}, d_{1}\right)-F_{1}\left(a_{11}\right)}{f_{1}\left(a_{12}\right)}$

And so on, we can get

$a_{j(i+1)}=\frac{\gamma_{1}\left(c_{j}, d_{j}\right)-F_{j}\left(a_{j(i-1)}\right)}{f_{j}\left(a_{j i}\right)} i=1,2, \ldots \quad j=1,2, \ldots, \ldots n$

By similar way we can prove equation (4).

\section{Theorem 3}

If $\Phi=\left(\Phi_{1}, \Phi_{2}, \ldots \Phi_{n}\right) \in \widehat{\Phi}$ is an optimal search plan, then:

$f_{j}\left(a_{j(i+1)}\right)<f_{j}\left(a_{j i}\right) \quad \forall_{i} \geq 1, j=1,2, \ldots . n$

And

$f_{j}\left(b_{j(i+1)}\right)<f_{j}\left(b_{j i}\right) \quad \forall_{i} \geq 1, j=1,2, \ldots . n$

\section{Proof}

We obtain from (3) and further from the definition of the search plan:

$f_{j}\left(a_{j i}\right)=\frac{\gamma_{j}\left(c_{j}, d_{j}\right)-F_{j}\left(a_{j(i-1)}\right)}{a_{j(i+1)}} ; i \geq 3$

Thus, on the line $\mathrm{L}_{1}$ we can get :

$f_{j}\left(a_{1 i}\right)=\frac{\gamma_{1}\left(c_{1}, d_{1}\right)-F_{1}\left(a_{1(i-1)}\right)}{a_{1(i+1)}} ; i \geq 3$

$f_{j}\left(a_{12}\right)=\frac{\gamma_{1}\left(c_{1}, d_{1}\right)-F_{1}\left(a_{11}\right)}{a_{13}} ; \mathrm{j}=1, i=2$

And

$f_{j}\left(a_{11}\right)=\frac{\gamma_{1}\left(c_{1}, d_{1}\right)-F_{1}(0)}{a_{12}} ; \mathrm{j}=1, i=1$

But

$\gamma_{1}\left(\mathrm{c}_{1}, \mathrm{~d}_{1}\right)-\mathrm{F}_{1}(0)>\gamma_{1}\left(\mathrm{c}_{1}, \mathrm{~d}_{1}\right)-\mathrm{F}_{1}\left(\mathrm{a}_{11}\right)>\ldots . \gamma_{1}\left(\mathrm{c}_{1}, \mathrm{~d}_{1}\right)-\mathrm{F}_{1}\left(\mathrm{a}_{1(\mathrm{i}-1)}\right) ; \mathrm{i} \geq 3$

and $\mathrm{a}_{12}<\mathrm{a}_{13}<\ldots<\mathrm{a}_{1(\mathrm{i}-1)}$

Hence:

$\frac{\gamma_{1}\left(c_{1}, d_{1}\right)-F_{1}(0)}{a_{12}}>\frac{\gamma_{1}\left(c_{1}, d_{1}\right)-F_{1}\left(a_{11}\right)}{a_{13}}>\ldots . .>\frac{\gamma_{1}\left(c_{1}, d_{1}\right)-F_{1}\left(a_{1(i-1)}\right)}{a_{1(i+1)}}$

Thus,

$F_{1}\left(\mathrm{a}_{11}\right)>f_{1}\left(\mathrm{a}_{12}\right)>\ldots>f_{1}\left(\mathrm{a}_{1 \mathrm{i}}\right), \mathrm{i} \geq 3$ and $\mathrm{j}=1,2, \ldots \mathrm{n}$

By the same steps, we get the following at the line $\mathrm{L}_{j}$;

$\gamma_{\mathrm{j}}\left(\mathrm{a}_{11}\right)>f_{1}\left(\mathrm{a}_{12}\right)>\ldots . .>f_{1}\left(\mathrm{a}_{1 \mathrm{i}}\right), \mathrm{i} \geq 3$, and $\mathrm{j}=1,2, \ldots \mathrm{n}$

By the same steps, we get the following at the line $\mathrm{L}_{\mathrm{j}}$;

$\gamma_{j}\left(c_{j}, d_{j}\right)-F_{j}(0)>\gamma_{j}\left(c_{j}, d_{j}\right)-F_{j}\left(a_{j 1}\right)>\ldots .>\gamma_{j}\left(c_{j}, d_{j}\right)-F_{j}\left(a_{j(i-1)}\right) ; i \geq 3$
Hence

$\frac{\gamma_{j}\left(c_{j}, d_{j}\right)-F_{j}(0)}{a_{j 2}}>\frac{\gamma_{j}\left(c_{j}, d_{j}\right)-F_{j}\left(a_{j 1}\right)}{a_{j 3}}>\ldots . .>\frac{\gamma_{j}\left(c_{j}, d_{j}\right)-F_{j}\left(a_{j(i-1)}\right)}{a_{j(i+1)}}$

Thus;

$F_{1}\left(\mathrm{a}_{\mathrm{j} 2}\right)>f_{1}\left(\mathrm{a}_{\mathrm{j} 3}\right)>\ldots .>f_{\mathrm{j}}\left(\mathrm{a}_{\mathrm{j}(\mathrm{i}+1)}\right)$,

Therefore:

$f_{j}\left(a_{j(i+1)}\right)<f_{j}\left(a_{j i}\right) \quad \forall_{i} \geq 1, j=1,2, \ldots . n$

By similar way we can prove equation (6).

\section{Theorem 4}

If $\mathrm{X}_{\mathrm{j}}$ the position of the target on the line $\mathrm{L}_{\mathrm{j}}$, which have the uniform distribution with the probability density function:

$$
f_{j}\left(x_{j}\right)=\frac{1}{2 k_{j}} ;-k_{j} \leq x_{j} \leq k_{j} \quad j=1,2, \ldots . n
$$

Then

$\mathrm{E}[\mathrm{D}(\phi)]=2 \mathrm{k}_{\mathrm{j}}$.

\section{Proof}

The searchers $S_{2 j-1}$ and $S_{2 j}$ start together from the origin of the line $L_{j}$. Let $\phi_{\mathrm{jr}}=\left(\phi_{1 \gamma}, \phi_{2 \gamma}, \ldots . ., \phi_{\mathrm{n} \gamma}\right) \in \phi_{0}$ be a search plans and $\mathrm{E}\left[\mathrm{D}\left(\phi_{\gamma}\right)\right] ; \gamma=1,2,3$,

$\mathrm{J}=1,2, \ldots \mathrm{n}$.

1. suppose that $\phi_{j 1}$ consists of the points $\left\{-\mathrm{k}_{\mathrm{i}}, 0, \mathrm{k}_{\mathrm{j}}\right\}$

If $0<\mathrm{x}_{\mathrm{j}} \leq \mathrm{k}_{\mathrm{j}}$, then $\mathrm{D}_{2 \mathrm{j}}=2 \mathrm{k}_{\mathrm{j}}$

If $-\mathrm{k}_{\mathrm{j}} \leq \mathrm{x}_{\mathrm{j}}<0$, then $\mathrm{D}_{2 \mathrm{j}-1}=2 \mathrm{k}_{\mathrm{j}}$

Hence, the expectation can be obtained as follows:

$E\left[D\left(\Phi_{j 1}\right)\right]=\frac{1}{2 k_{j}}\left(\int_{0}^{k_{j}} 2 k_{j} d x+\int_{-k_{j}}^{0} 2 k_{j} d x=2 k_{j}\right)$

2. Suppose that $\phi_{\mathrm{j} 2}$ consists of the points $\left\{-\mathrm{k}_{\mathrm{j}},-\mathrm{a}_{\mathrm{j} 1}, 0 \mathrm{a}_{\mathrm{j} 1}, \mathrm{k}_{\mathrm{j}}\right\}$

If $0<x_{j} \leq a_{j 1}$ Then $D_{2 j}=2 a_{j 1}$,

If $\mathrm{a}_{\mathrm{j} 1}<\mathrm{x}_{\mathrm{j}} \leq \mathrm{k}_{\mathrm{j}}$ then $\mathrm{D}_{2 \mathrm{j}}=2 \mathrm{a}_{\mathrm{j} 1}+2 \mathrm{k}_{\mathrm{j}}$

If $-a_{j 1} \leq x_{j}<0$, then $D_{2 j-1}=2 a_{j 1}$

If $-\mathrm{k}_{\mathrm{j}} \leq \mathrm{x}_{\mathrm{j}}<-\mathrm{a}_{\mathrm{j} 1}$, then $\mathrm{D}_{2 \mathrm{j}-1}=2 \mathrm{a}_{\mathrm{j} 1}+2 \mathrm{k}_{\mathrm{j}}$

Hence, the expectation can be obtained as follows:

$E\left[D\left(\Phi_{j 2}\right)\right]=\frac{2}{2 k_{j}}\left(\int_{0}^{a_{j 1}} 2 a_{j 1} d x+\int_{a_{j 1}}^{k_{j}}\left(2 \mathrm{a}_{j 1}+2 \mathrm{k}_{j}\right) \mathrm{dx}\right)=2 k_{j}$

3. Suppose that $\phi_{j 3}$ consists of the points $\left\{-\mathrm{k}_{\mathrm{j}},-\mathrm{a}_{\mathrm{j} 2},-\mathrm{a}_{\mathrm{j} 1}, 0, \mathrm{a}_{\mathrm{j} 1}, \mathrm{a}_{\mathrm{j} 2}, \mathrm{k}_{\mathrm{j}}\right\}$

If $0<x_{j} \leq a_{j 1}$ Then $D_{2 j}=2 a_{j 1}$,

If $a_{j 1}<x_{j} \leq a_{j 2}$, then $D_{2 j}=2 a_{j 1}+2 a_{j 2}$

If $\mathrm{a}_{\mathrm{j} 2}<\mathrm{x}_{\mathrm{j}} \leq \mathrm{k}_{\mathrm{j}}$ then $\mathrm{D}_{2 \mathrm{j}}=2 \mathrm{a}_{\mathrm{j} 1}+2 \mathrm{a}_{\mathrm{j} 2}+2 \mathrm{k}_{\mathrm{j}}$

If $-a j_{1} \leq x_{j}<0$, then $D_{2 j-1}=2 a_{j 1}$

If $-a_{j 2} \leq x_{j}<-a_{j 1}$, then $D_{2 j-1}=2 a_{j 1}$

If $-\mathrm{k}_{\mathrm{j}} \leq \mathrm{x}_{\mathrm{j}}<-\mathrm{a}_{\mathrm{j} 2}$ then $\mathrm{D}_{2 \mathrm{j}-1}=2 \mathrm{a}_{\mathrm{j} 1}+2 \mathrm{a}_{\mathrm{j} 2}+2 \mathrm{k}_{\mathrm{j}}$.

Hence, the expectation can be obtained as follows 


$$
\begin{aligned}
E\left[D\left(\Phi_{j 3}\right)\right] & =\frac{2}{2 k_{j}}\left(\int_{0}^{a_{j 1}} 2 a_{j 1} d x+\int_{a_{j 1}}^{k_{j}}\left(2 \mathrm{a}_{j 1}+2 a_{j 2}\right) \mathrm{dx}+\int_{a_{j 2}}^{k_{j}}\left(2 a_{j 1}+2 a_{j 2}+2 k_{j}\right) \mathrm{dx}\right) \\
& =2 k_{j}+2 a_{j 1}\left(\frac{a_{j 2}}{k_{j}}\right)
\end{aligned}
$$

Hence, the optimal search plans are $\phi_{1}$ or $\phi_{2}$ for any $0<\mathrm{a}_{\mathrm{j} 1}<\mathrm{k}_{\mathrm{j}}$.

\section{Note that-}

If $\mathrm{k}_{\mathrm{j}}=1$ then we obtain the same results of Diana [22].

\section{Example 1}

Let $(n=2)$, then we have two disjoint lines $\mathrm{L}_{1}$ and $\mathrm{L}_{2}$ and four searchers $S_{1}, S_{2}, S_{3}$ and $S_{4}$ each of them start together from the origin.

If $\mathrm{X}_{1}$ the position of the target on the line, which has the uniform distribution with the probability density function

$$
f_{1}\left(x_{1}\right)=\frac{1}{12} ;-6 \leq x_{1} \leq 6 \quad \text { where } c_{1}=-3 \text { and } d_{1}=3
$$

And $\mathrm{X}_{2}$ the position of the target on the line $\mathrm{L}_{2}$, which has the uniform distribution with the probability density function

$$
f_{2}\left(x_{2}\right)=\frac{1}{8} ;-40 \leq x_{2} \leq 4 \quad \text { where } c_{2}=-2 \text { and } d_{2}=2
$$

We have the following search plans $\phi_{\mathrm{jr}}=\left(\phi_{1 \gamma}, \phi_{2 \gamma}\right) \in \phi_{0}$ and $\mathrm{E}\left[\mathrm{D}\left(\phi_{\gamma}\right)\right] ; \gamma=1,2,3$.

1. suppose that $\phi_{11}$ consists of the points $\{-3,0,3\}$ and $\phi_{21}$ consists of the points $\{-2,0,2\}$

$$
\begin{aligned}
& \text { If } 0<\mathrm{x}_{1} \leq 3, \quad \text { then } \mathrm{D}_{2}=6 \\
& \text { If }-3 \leq \mathrm{x}_{1}<0, \quad \text { then } \mathrm{D}_{1}=6 \\
& \text { If } 0<\mathrm{x}_{2} \leq 2 \text {, then } \mathrm{D}_{3}=4 \\
& \text { If }-2 \leq \mathrm{x}_{2}<0 \quad \text { then } \mathrm{D}_{3}=4
\end{aligned}
$$

Hence, the expectation can be obtained as follows

$$
E[D(\Phi)]=6\left(\int_{0}^{3} \frac{1}{12} d x_{1}+\int_{-3}^{0} \frac{1}{12} \mathrm{dx}_{1}\right)+4\left(\int_{0}^{2} \frac{1}{8} d x_{2}+\int_{-2}^{0} \frac{1}{8} d x_{2}\right)=5
$$

2. suppose that $\phi_{12}$ consists of the points $\{-3,-2,0,2,3\}$ and $\phi_{22}$ consists of the points $\{-2,-1,0,1,2\}$

$$
\begin{array}{ll}
\text { If } 0<\mathrm{x}_{1} \leq 2, & \text { then } \mathrm{D}_{2}=4 \\
\text { If } 2<\mathrm{x}_{1} \leq 3, & \text { then } \mathrm{D}_{2}=10 \\
\text { If }-2 \leq \mathrm{x}_{1}<0, & \text { then } \mathrm{D}_{1}=4 \\
\text { If }-3 \leq \mathrm{x}_{1}<-2 & \text { then } \mathrm{D}_{1}=10 \\
\text { If } 0<\mathrm{x}_{2} \leq 1, & \text { then } \mathrm{D}_{4}=2 \\
\text { If } 1<\mathrm{x}_{2}<2, & \text { then } \mathrm{D}_{4}=6 \\
\text { If }-1 \leq \mathrm{x}_{2}<0, & \text { then } \mathrm{D}_{3}=2 \\
\text { If }-2 \leq \mathrm{x}_{2}<-1, & \text { then } \mathrm{D}_{3}=6
\end{array}
$$

Hence, the expectation can be obtained as follows:

$$
\begin{aligned}
E[D(\Phi)]= & 4 \int_{0}^{2} \frac{1}{12} d x_{1}+10 \int_{-3}^{0} \frac{1}{12} \mathrm{dx}_{1}+4 \int_{-2}^{0} \frac{1}{12} d x_{1}+10 \int_{-3}^{-2} \frac{1}{12} d x_{1} \\
& +2 \int_{0}^{1} \frac{1}{8} d x_{2}+6 \int_{1}^{2} \frac{1}{8} d x_{2}+2 \int_{-1}^{0} \frac{1}{8} d x_{2}+6 \int_{-2}^{-1} \frac{1}{8} d x_{2}=5
\end{aligned}
$$

3. suppose that $\phi_{13}$ consists of the points $\{-3,-2,-1,0,1,2,3\}$ and $\phi_{23}$ consists of the points $\{-2,-1,-0.5,0,0.5,1,2\}$

$$
\text { If } 0<x_{1} \leq 1, \quad \text { then } \mathrm{D}_{2}=2 \text {, }
$$

$$
\begin{array}{ll}
\text { If } 1<\mathrm{x}_{1} \leq 2, & \text { then } \mathrm{D}_{2}=6, \\
\text { If } 2<\mathrm{x}_{1} \leq 3, & \text { then } \mathrm{D}_{2}=12 \\
\text { If }-1 \leq \mathrm{x}_{1}<0, & \text { then } \mathrm{D}_{1}=2 \\
\text { If }-2 \leq \mathrm{x}_{1}<-1, & \text { then } \mathrm{D}_{1}=6 \\
\text { If }-3 \leq \mathrm{x}_{1}<-2, & \text { then } \mathrm{D}_{1}=12 \\
\text { If } 0<\mathrm{x}_{2} \leq 0.5, & \text { then } \mathrm{D}_{4}=1, \\
\text { If } 0.5<\mathrm{x}_{2} \leq 1, & \text { then } \mathrm{D}_{4}=3 \\
\text { If } 1<\mathrm{x}_{2} \leq 2, & \text { then } \mathrm{D}_{4}=7 \\
\text { If }-0.5 \leq \mathrm{x}_{2}<0 & \text { then } \mathrm{D}_{3}=1 \\
\text { If }-1 \leq \mathrm{x}_{2}<-0.5, & \text { then } \mathrm{D}_{3}=3 \\
\text { If }-2 \leq \mathrm{x}_{2}<-1 & \text { then } \mathrm{D}_{3}=7
\end{array}
$$

Hence, the expectation can be obtained as follows

$$
\begin{aligned}
E[D(\Phi)]= & 2 \int_{0}^{1} \frac{1}{12} d x_{1}+6 \int_{1}^{2} \frac{1}{12} \mathrm{dx}_{1}+12 \int_{2}^{3} \frac{1}{12} d x_{1}+2 \int_{-3}^{-2} \frac{1}{12} d x_{1} \\
& +6 \int_{-2}^{-1} \frac{1}{12} d x_{1}+12 \int_{-3}^{-2} \frac{1}{12} d x_{1}+2 \int_{0}^{0.5} \frac{1}{8} d x_{2}+3 \int_{0.5}^{-1} \frac{1}{8} d x_{2}=5 \\
& +7 \int_{-2}^{-1} \frac{1}{8} d x_{2}+\int_{-0.5}^{0} \frac{1}{8} d x_{2}+3 \int_{-1}^{-0.5} \frac{1}{8} d x_{2}+7 \int_{-2}^{-1} \frac{1}{8} d x_{2}=6.08333333
\end{aligned}
$$

Hence, the optimal search plans are $\phi_{11}$ or $\phi_{22}$.

\section{Case (2)}

Un-symmetric coordinated search for a randomly located target on the one of $\mathrm{n}$ disjoint lines.

This case concerned with the coordinated search that is the position of the lost target has an un-symmetric distribution, it means that each searchers $\mathrm{S}_{2 \mathrm{j}-1}$ and $\mathrm{S}_{2 \mathrm{j}}$ of them starts looking for the target from the origin on $\mathrm{L}_{\mathrm{i}}$. They move with different distances according to the probability of the position of the lost target on the line $\mathrm{L}_{j}$. The target is the same randomly located according to a known un-symmetric distribution on all lines with different distances. It means that the distance which the searchers $S_{2 j-1}$ of the all line are equal, and the distance which the searchers $S_{2 j}$ of the all line are equal.

We assume that the time which the searcher $S_{2 j-1}$ equal to $D_{2 j-1}$ and the time which the searcher $S_{2}$ equal to $D_{2 j}$ on the line $L_{\text {.j }}$. In the following theorem, we assume each case when $D_{2 j-1}<D_{2 j}$ or $D_{2 j}>D_{2 j-1}$ according to the un-symmetric distribution of the lost target.

\section{Theorem 5}

The expected value of the time for the searchers to return to the origins, until one of them has found a target is given by:

$$
a_{j i}\left[1-\gamma_{1}\left(b_{j(i-1)}, \mathrm{a}_{j(i-1)}\right)-2 \sum_{i=1}^{\infty} \sum_{j=1}^{n}\left\{\mathrm{~b}_{j i}\left[1-\gamma_{j}\left(b_{j(i-1)}, a_{j(i-1)}\right)\right]\right\}\right], i, j \geq 1
$$

\section{Proof}

1. If $D_{2 j-1}>D_{2 j}$ in this case we use the greater time $D_{1}$ as the time of finding the target in the following we find:

If the target lies in $\left[0, \mathrm{a}_{j 1}\right]$, then $\mathrm{D}_{2 \mathrm{j}-1}=2 \mathrm{a}_{\mathrm{j} 1}$

If the target lies in $\left[\mathrm{a}_{\mathrm{j} 1}, \mathrm{a}_{\mathrm{j} 2}\right]$, then $\mathrm{D}_{2 \mathrm{j}-1}=2\left[\mathrm{a}_{\mathrm{j} 1}+\mathrm{a}_{\mathrm{j} 2}\right]$

If the target lies in $\left[a_{j 2}, a_{j 3}\right]$,then, $D_{2 j-1}=2\left[a_{j 1}+a_{j 2}+a_{j 3}\right]$

and so on. 
If the target lies in $\left[\mathrm{b}_{\mathrm{j} 1}, 0\right]$ then $\mathrm{D}_{2 \mathrm{j}-1}=2 \mathrm{a}_{\mathrm{j} 1}$.

If the target lies in $\left[b_{j 2}, b_{j 1}\right]$ then $D_{2 j-1}=2\left[a_{j 1}+a_{j 2}\right]$

If the target lies in $\left[\mathrm{b}_{\mathrm{i} 3}, \mathrm{~b}_{\mathrm{j} 2}\right]$ then $\mathrm{D}_{2 \mathrm{j}-1}=2\left[\mathrm{a}_{\mathrm{j} 1}+\mathrm{a}_{\mathrm{j} 2}+\mathrm{a}_{\mathrm{j} 3}\right]$

and so on.

2. If $\mathrm{D}_{2 j}>\mathrm{D}_{2 \mathrm{j}-1}$ in this case we use the greater time $\mathrm{D}_{2}$ as the time of finding the target in the following we find :

If the target lies in $\left[0, a_{j 1}\right]$, then $D_{2 j}>D_{2 j-1}=-2 b_{j 1}$.

If the target lies in $\left[a_{j 1}, a_{j 2}\right]$, then $D_{2 j}>D_{2 j-1}=-2\left[b_{j 1}+b_{j 2}\right]$

If the target lies in $\left[a_{j 2}, a_{j 3}\right]$, then $D_{2 j}>D_{2 j-1}=-2\left[b_{j 1}+b_{j 2}+b_{j 3}\right]$

and so on.

If the target lies in $\left[b_{j 1}, 0\right]$, then $D_{2 j}>D_{2 j-1}=-2 b_{j 1}$

If the target lies in $\left[b_{j 2}, b_{j 1}\right]$, then $D_{2 j}>D_{2 j-1}=-2\left[b_{j 1}+b_{j 2}\right]$

If the target lies in $\left[b_{j 2}, b_{j 3}\right]$, then $D_{2 j}>D_{2 j-1}=-2\left[b_{j 1}+b_{j 2}+b_{j 3}\right]$

and so on.

According to our assumption that the position of the target has an un-symmetric distribution. Hence,

$$
\begin{aligned}
& E[D(\Phi)]=\sum_{j=1}^{n}\left\{2 \mathrm{a}_{j 1} \gamma_{j}\left(0, a_{j 1}\right)+2\left[a_{j 1}+a_{j 2}\right] \gamma_{j}\left(a_{j 1}, a_{j 2}\right)\right\} \\
& +2\left[\mathrm{a}_{j 1}+\mathrm{a}_{j 2}+\mathrm{a}_{j 3}\right] \gamma_{j}\left(a_{j 2}, a_{j 3}\right)+\ldots \\
& +2 a_{j 1} \gamma_{j}\left(b_{j 1}, 0\right)+2\left[\mathrm{a}_{j 1}+\mathrm{a}_{j 2}\right] \gamma_{j}\left(b_{j 2}, b_{j 1}\right) \\
& +2\left[\mathrm{a}_{j 1}+\mathrm{a}_{j 2}+\mathrm{a}_{j 3}\right] \gamma_{j}\left(b_{j 3}, b_{j 2}\right)+\ldots . \\
& -2 b_{j 1} \gamma_{j}\left(0, a_{j 1}\right)-2\left[b_{j 1}+b_{j 2}\right] \gamma_{j}\left(a_{j 1}, a_{j 2}\right) \\
& -2\left[b_{j 1}+b_{j 2}+b_{j 3}\right] \gamma_{j}\left(a_{j 2}, a_{j 3}\right)-\ldots . . \\
& -2 b_{j 1} \gamma_{j}\left(b_{j 1}, 0\right)-2\left[b_{j 1}+b_{j 2}\right] \gamma_{j}\left(b_{j 2}, b_{j 1}\right) \\
& \left.-2\left[b_{j 1}+b_{j 2}+b_{j 3}\right] \gamma_{j}\left(b_{j 3}, b_{j 2}\right)-\ldots . .\right\} \\
& =\sum_{j=1}^{n}\left\{2 \mathrm{a}_{j 1}\left[\begin{array}{l}
\gamma_{j}\left(0, a_{j 1}\right)+\gamma_{j}\left(a_{j 1}, a_{j 2}\right)+\gamma_{j}\left(a_{j 2}, a_{j 3}\right)+\ldots . \\
+\gamma_{j}\left(b_{j 1}, 0\right)+\gamma_{j}\left(b_{j 2}, b_{j 1}\right)+\gamma_{j}\left(b_{j 3}, b_{j 2}\right)+\ldots
\end{array}\right]\right\} \\
& +2 a_{j 2}\left[\begin{array}{l}
\gamma_{j}\left(a_{j 1}, a_{j 2}\right)+\gamma_{j}\left(a_{j 2}, a_{j 3}\right)+\ldots \\
+\gamma_{j}\left(b_{j 2}, b_{j 1}\right)+\gamma_{j}\left(b_{j 3}, b_{j 2}\right)+\ldots
\end{array}\right] \\
& +2 a_{j 3}\left[\begin{array}{l}
\gamma_{j}\left(a_{j}, a_{j 3}\right)+\gamma_{j}\left(a_{j 3}, a_{j 4}\right)+\ldots . \\
+\gamma_{j}\left(b_{j 3}, b_{j 2}\right)+\gamma_{j}\left(b_{j 4}, b_{j 3}\right)+\ldots
\end{array}\right] \\
& -2 b_{j 1}\left[\begin{array}{l}
\gamma_{j}\left(0, a_{j 1}\right)+\gamma_{j}\left(a_{j 1}, a_{j 2}\right)+\gamma_{j}\left(a_{j 2}, a_{j 3}\right)+\ldots \\
\gamma_{j}\left(b_{j 1}, 0\right)+\gamma_{j}\left(b_{j 2}, b_{j 1}\right)+\gamma_{j}\left(b_{j 3}, b_{j 2}\right)+\ldots .
\end{array}\right] \\
& -2 b_{j 2}\left[\begin{array}{l}
\gamma_{j}\left(\mathrm{a}_{j 1}, a_{j 2}\right)+\gamma_{j}\left(a_{j 2}, a_{j 3}\right)+\ldots \\
\gamma_{j}\left(b_{j 2}, \mathrm{~b}_{j 1}\right)+\gamma_{j}\left(b_{j 3}, b_{j 2}\right)+\ldots .
\end{array}\right] \\
& -2 b_{j 3}\left[\begin{array}{l}
\gamma_{j}\left(\mathrm{a}_{j 2}, a_{j 3}\right)+\gamma_{j}\left(a_{j 3}, a_{j 4}\right)+\ldots \\
\gamma_{j}\left(b_{j 3}, \mathrm{~b}_{j 2}\right)+\gamma_{j}\left(b_{j 4}, b_{j 3}\right)+\ldots .
\end{array}\right] \\
& =\sum_{j=1}^{n} \quad \begin{array}{l}
\left\{\mathrm{a}_{j 1}+2 \mathrm{a}_{j 2}\left[1-\gamma_{j}\left(b_{j 1}, a_{j 1}\right)\right]+2 \mathrm{a}_{j 3}\left[1-\gamma_{j 1}\left(b_{j 2}, \mathrm{a}_{j 2}\right)\right]+\ldots\right. \\
\left.\mathrm{b}_{j 2}\left[1-\gamma_{j}\left(b_{j 1}, a_{j 1}\right)-2 b_{j 3}\left[1-\gamma_{j}\left(b_{j 2}, a_{j 2}\right)\right]-\ldots\right]\right\}
\end{array} \\
& =2 \sum_{i=1}^{\infty} \sum_{j=1}^{n}\left\{\mathrm{a}_{j 1}\left[1-\gamma_{j}\left(b_{j(i-1)}, a_{j(i-1)}\right)\right]\right\}-2 \sum_{i=1}^{\infty} \sum_{j=1}^{n}\left\{\mathrm{~b}_{j i}\left[1-\gamma_{j}\left(b_{j(i-1)}, a_{j(i-1)}\right)\right]\right\}
\end{aligned}
$$

\section{Special cases}

\section{Case 1}

If the target is located on one line and has un-symmetric distribution around $\mathrm{a}_{0}=\mathrm{b}_{0}=0$ in relation $(7)$ we find :

$$
E[D(\Phi)]=\sum_{j=1}^{n} \mathrm{a}_{i}\left[1-\gamma\left(b_{(\mathrm{i}-1)}, a_{(\mathrm{i}-1)}\right)\right]-2 \sum_{i=1}^{\infty}\left\{\mathrm{b}_{i}\left(1-\gamma\left(b_{(\mathrm{i}-1)}, a_{(\mathrm{i}-1)}\right)\right)\right\}
$$

\section{Case 2}

If the target is located according to an un symmetric distribution on one of two disjoint lines $\mathrm{L}_{1}$ and $\mathrm{L}_{2}$, we have four searchers start together from the origin then we can get:

$$
E[D(\Phi)]=\sum_{j=1}^{n} \mathrm{a}_{i}\left[1-\gamma_{1}\left(b_{(\mathrm{i}-1)}, a_{(\mathrm{i}-1)}\right)\right]-\gamma_{2}\left(b_{(\mathrm{i}-1)}, a_{(\mathrm{i}-1)}\right)
$$

\section{Theorem 6}

Let $\mathrm{F}_{j}(\mathrm{xj})$ be the distribution function of a continuous random variable $\mathrm{x}_{\mathrm{j}}$ with a density function $f_{j}\left(\mathrm{x}_{\mathrm{j}}\right)$ and if

$$
\begin{aligned}
& \Phi=\left(\Phi_{1}, \Phi_{2}, \ldots \Phi_{n}\right) \in \Phi \text { is an optimal search plan, then } \\
& a_{j(\mathrm{i}+1)}=\frac{\left[1-\gamma_{j}\left(b_{j(i-1)}, a_{j(i-1)}\right)\right]}{f_{j}\left(a_{j i}\right)}+b_{j(i+1)} \\
& b_{j(\mathrm{i}+1)}=\frac{\left[1-\gamma_{j}\left(b_{j(i-1)}, a_{j(i-1)}\right)\right]}{-f_{j}\left(b_{j i}\right)}+a_{j(i+1)} \\
& \text { Proof }
\end{aligned}
$$

From (7) we have:

$$
\begin{aligned}
E[D(\Phi)] & =\sum_{j=1}^{n} \mathrm{a}_{i}\left[1-\gamma_{1}\left(b_{(\mathrm{i}-1)}, a_{(\mathrm{i}-1)}\right)+2 a_{j 3}\right]\left[1-\gamma_{j}\right]\left(b_{j 2}, a_{j 2}\right)+\ldots-2 b_{j 1} \\
& \left.-2 b_{j 2}\left[1-\gamma_{j}\left(b_{j 1}, a_{j 1}\right)\right]-2 b_{j 3}\left[1-\gamma_{j}\left(b_{j 2}, a_{j 2}\right)\right] \ldots\right\} \\
& =\left\{2 \mathrm{a}_{11}+2 \mathrm{a}_{12}\left[1-\gamma_{1}\left(b_{11}, a_{11}\right)\right]+2 \mathrm{a}_{13}\left[1-\gamma_{1}\left(b_{12}, a_{12}\right)\right]+\ldots .\right\} \\
& +\left\{2 \mathrm{a}_{21}+2 \mathrm{a}_{22}\left[1-\gamma_{2}\left(b_{21}, a_{21}\right)\right]+2 \mathrm{a}_{23}\left[1-\gamma_{2}\left(b_{22}, a_{22}\right)\right]+\ldots\right\} \\
& +\left\{2 \mathrm{a}_{31}+2 \mathrm{a}_{32}\left[1-\gamma_{3}\left(b_{31}, a_{31}\right)+2 a_{33}\left[1-\gamma_{3}\left(b_{32}, a_{32}\right)\right]\right]\right\}+\ldots \\
& \left.-2 \mathrm{~b}_{11}-2 b_{12}\left[1-\gamma_{1}\left(b_{11}, a_{11}\right)\right]-2 b_{13}\left[1-\gamma_{1}\left(b_{12}, a_{12}\right)\right]-\ldots .\right\} \\
& \left.-2 b_{21}-2 b_{22}\left[1-\gamma_{2}\left[b_{21}, a_{21}\right]-2 b_{23}\left[1-\gamma_{2}\left(b_{22}, a_{22}\right)\right]\right]-\ldots\right\} \\
& \left.-2 b_{31}-2 b_{32}\left[1-\gamma_{3}\left(b_{31}, a_{31}\right)\right]-2 b_{33}\left[1-\gamma_{3}\left(b_{32}, a_{32}\right)\right]-\ldots . .\right\}
\end{aligned}
$$

Then

$$
\frac{\partial E(D(\Phi))}{\partial a_{11}}=2-2 a_{12} f_{1}\left(a_{11}\right)+2 b_{11} f_{1}\left(a_{11}\right)=0
$$

Which leads to

$a_{12}=\frac{1}{f_{1}\left(a_{11}\right)}+b_{12}$

also,

$\frac{\partial E(D(\Phi))}{\partial a_{12}}=\left[1-\gamma_{1}\left(b_{11}, a_{11}\right)\right]-2 a_{13} f_{1}\left(a_{12}\right)+2 b_{13} f_{1}\left(a_{12}\right)=0$

due to

$a_{13}=\frac{\left[1-\gamma_{1}\left(b_{11}, a_{11}\right)\right]}{f_{1}\left(a_{12}\right)}+b_{13}$

similarly, then

$\frac{\partial E(D(\Phi))}{\partial a_{12}}=\left[1-\gamma_{1}\left(b_{12}, a_{12}\right)\right]-2 a_{14} f_{1}\left(a_{13}\right)+2 b_{14} f_{1}\left(a_{13}\right)=0$

due to 
Citation: Teamah AEAM, Gabal HMA, Elbery AB (2018) Quasi-Coordinated Search for a Randomly Located Target. J Appl Computat Math 7: 395. doi: 10.4172/2168-9679.1000395

Page 7 of 7

$$
a_{14}=\frac{\left[1-\gamma_{1}\left(b_{j(i-1)}, a_{j(i-1)}\right)\right]}{f_{j}\left(a_{j i}\right)}+b_{j(i+1)} \quad j=1,2, \ldots . n \quad i \geq 1
$$

by similar way we can prove (9).

\section{References}

1. Stone LD (1975) Theory of Optimal Search Academic Press, New York.

2. El-Rayes AB, Abd El-Moneim AM, Fergani H (1993) On The Generalized Linear Search Problem. Delta Journal pp: 1-10.

3. Hadidy MAE, Mohamed AMA, Gabal HMA (2000) Coordınated Search for a Randomly Located Target on the Plane. Eur J Pure Appl Math 2.

4. Abd-Elmonein AM, Hamdy MAG (2003) Linear Search With Multiple Searchers for a Randomly Moving Target. International Conference for Statistics, Computer Science and its Application. pp: 115-124.

5. Beck A (1964) On the linear search problem. Israel J Math 2: 221-228.

6. Beck A (1965) More on the linear search problem. Israel J Math 3: 61-70.

7. Beck A, Beck M (1984) The son of the linear search problem. Israel J Math 48:109-122.

8. Beck A, Beck M (1986) The linear search problem rides again. Israel J Math 53: 365- 372.

9. Beck A, Beck M (1992) The revenge of the linear search problem. SIAM J Control Optim 30: 112-122.

10. Beck A, Newman D (1970) Yet more on the linear search problem. Israel J Math 8: 419-429.

11. Beck A, Warren P (1965) The return of the linear search problem. Israel J Math 10: $169-183$
12. Franck W (1965) On an optimal search problem. SIAM Rev 7: 503-512

13. Rousseeuw $P$ (1983) Optimal search paths for random variables. J Comput Appl Math 9: 279-286.

14. Reyniers D (1966) Coordinated search for an object on the line. Eur J Oper Res 95: 663-670.

15. Reyniers D (1995) Coordinated two searchers for an object hidden on an interval. J Oper Res Soc 46: 1386-1392.

16. Balkhi ZT (1987) The generalized linear search problem, existence of optimal search paths. J Oper Res. Soc 30: 399-420.

17. Balkhi ZT (1987) Generalized optimal search paths for continuous univariate random variable. Oper Res 23: 67-96.

18. Abd-Elmoneim A Mohamed, AbouGabal H, Afifi W (2007) On the coordinated search problem. Int J Pure Appl Math 5: 627-636.

19. Elbery AB (2007) Generalized and Multiplicative Linear Search Problem For Lost Targets, Tanta University

20. Abd-Elmoneim A Mohamed, AbouGabal HM, El-Hadidy MA (2009) Coordinated search for a randomly located target on the plane. European Journal of Pure and Applied Mathematics 297-111.

21. Abd-Elmoneim A Mohamed, Fergany HA El-Hadidy MA (2012) On the coordinated search problem on the plane, J Comput Mediat Commun, Istanbul University 41: 80-102.

22. Diana J, Reyniers (1995) Coordinated two Searchers for An Object Hidden on an Interval. J Oper Res Soc 46:1386-1392.

23. Diana J, Reyniers (1996) Coordinated Search for An Object On The Line. Eur J Oper Res 95: 663-670. 